\title{
Evaluation of Facility Management by Multivariate Statistics - Factor Analysis
}

\author{
Miloš Singovszki, Zuzana Vranayová \\ Technical University of Košice \\ Civil Engineering Faculty, Institute of Architectural Engineering \\ e-mail: milos.singovszki@tuke.sk,zuzana.vranayova@tuke.sk
}

\begin{abstract}
Facility management is evolving, there is no exact than other sciences, although its development is fast forward. The knowledge and practical skills in facility management is not replaced, on the contrary, they complement each other. The existing low utilization of science in the field of facility management is mainly caused by the management of support activities are many variables and prevailing immediate reaction to the extraordinary situation arising from motives of those who have substantial experience and years of proven experience. Facility management is looking for a system that uses organized knowledge and will form the basis, which grows from a wide range of disciplines. Significant influence on its formation as a scientific discipline is the "structure, which follows strategy". The paper deals evaluate technology building as part of an facility management by multivariate statistic - factor analysis.
\end{abstract}

Key words: facility management, technology building, factor analysis

\section{Introduction}

Facility management is a modern sector. Its application in the management of buildings contributes significantly to savings in operating costs and thereby increases the profitability of the business. It's not just a temporary trend in business management, but a practical way of professional management and enterprise resource management, which should be used continuously [1]. The content of services provided by the facility management is always what they consider the future management of the business client as an activity to be outsourced. The aim of this activity is to ensure the most efficient way to promote optimal activity at society. Facility manager, however, must understand all the primary processes and try to find the most effective for them to support and improve the current situation. The aim is not only support the primary process, but a permanent comprehensive development of the whole company, and thus the search for other supporting activities that it should help [2]. One possibility is the use of factor analysis, which aimed to create new variables and seeks to 
reduce the scale (reduction) of data with the minimum loss of information. Based on the assumption that the dependency between the monitored variables are brought about by a smaller number of standing behind the immeasurable variables, which are called common factors. These common factors are defined as a linear combination of original variables.

Factor analysis puts you directly in the main objective to know the structure and use of common factors that are considered as underlying causes of mutually correlated variables, and wants the best and easiest to explain and clarify the observed dependence [3].

\section{Materials and methods}

Experimental research was conducted in an office building - Košice City Hall, located on the Trieda SNP in Kosice. It is the largest office complex in the city, which was built in 1985. Currently it resides Municipality. The heat source is provided by existing exchanging station. Hydraulics central heating is classic. Central heating radiator circuits (social workers and technical rooms), air-conditioning circuit for central heating and air conditioning units for the circuit. Pressure protection system is based pressure expansion tank filling with air pressure of $100 \mathrm{kPa}$, and a safety valve opening pressure of $400 \mathrm{kPa}$. The primary heating medium is hot water $180 / 80^{\circ}$. Central heating system was designed in 1979 and the technical level is proportional to this year. Central heating radiator - heat transfer medium is hot water $92.5 / 67.5^{\circ}$, which is designed in the whole of $\mathrm{A}, \mathrm{B}, \mathrm{G}$, section $\mathrm{C}, \mathrm{D}$ are radiator heated corridors, stairwells, hygienically rooms and warehouses. Part $\mathrm{E}$ is heated by radiators entire northern facade, staircase, corridors, toilets and stores. Part F is a radiator covered the entire burden of winter theater, foyer, stairs, dressing rooms, storage rooms and social. Panes, air conditioning units are designed for all office rooms of parts C, D, $\mathrm{E}$, except the north façade. In the $\mathrm{F}$ units are equipped with study rooms and classrooms. Air conditioning units are panes in the winter, connected to the water supply $80 / 60{ }^{\circ}$. The circulation of heated water is forced hot water pumps.

Air conditioning units are panes for winter heating and summer cooling. The units operate with air circulation. Ventilation units are considered. Ventilated offices are windows. The size of the output units is determined according to the summer load [4].

Data was measured for ten variables (DS1 - Central heating temperature, DS2 - Hot water temperature - primary, DS3 - Temperature hot water - reverse, DS 4 - Outdoor temperature, DS5 - Air condition temperature, DS6 - Desired value calculated by the central heating, DS 7 - DHW set point, DS 8 - Air condition set point, DS 9 - Primary input, DS 10 - Primary reverse). The mean values for three years shows table 1 . 
Table 1: Mean values of ten variables in the experimental object

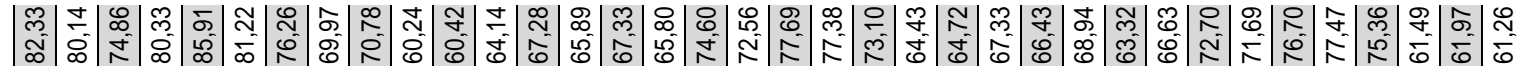

용

$\mathscr{O}:$.

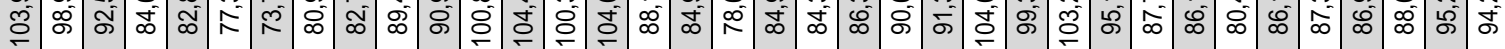

ڤ̆

×

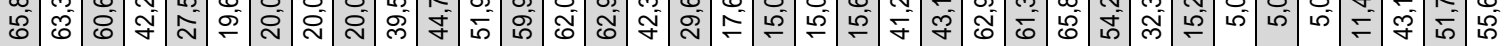

$\stackrel{\infty}{\circ}$

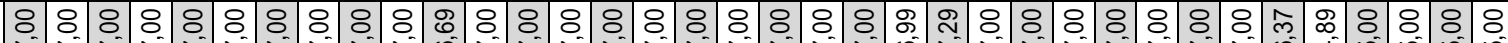

ڤ̆

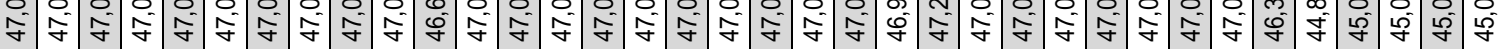

ஜ

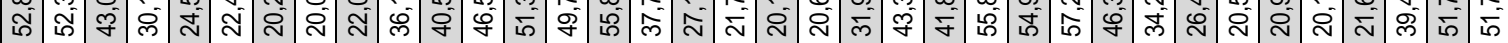

$\stackrel{\circ}{\circ}$

舟 ठأ

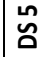

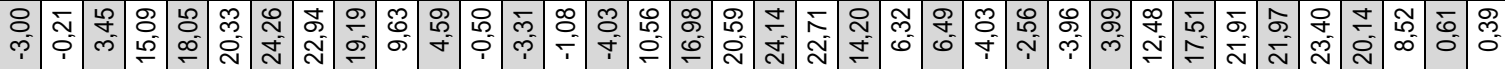

品 舟

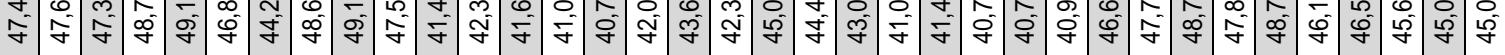

$\tilde{\check{a}}$

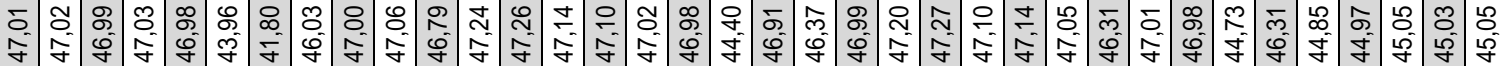

ณั

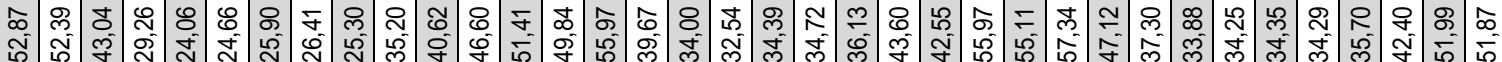
ลี 


\subsection{Factor analysis (FA)}

Factor analysis is a multivariate analytical technique, which derives a subset of uncorrelated variables called factors that explain the variance observed in the original dataset $[5,6,7]$. Factor analysis is used to unearth the latent structure of a set of variables. The factor analysis attempts to identify few factors that are responsible for the correlation among a large number of variables, it is also classified as a data reduction technique. The essential purpose of factor analysis is to describe, if possible, the covariance relationship among many variables in terms of a few underlying, but unobservable, random quantities called factors. The total variance of the indicator variables (the original variables) is decomposed into the following two components: First, variance that is common with general chemical level in the surface water is given by the square of the pattern loading (that is the correlation between any indicator and the factor); this part of the variance is referred to as the communality of the indicator with the common factor [8]. Second, variance that is in common with a specific factor is the variance of the variable minus the communality. This part of the variance is referred to as the unique/specific/error variance because it is unique to that particular variable. The common factors are unobservable. However, we can measure their indicators and compute the correlation among the indicators with the aim to identify the smallest number of common factors (that is most parsimonious factor model) that best explain the correlation among the variables; estimate pattern loadings, communalities, and the unique variance of the indicators [8]. The total number of factors generated from a typical factor analysis indicates the total number of possible sources of variation in the data. As we extract consecutive factors, they account for less and less variability. The decision of when to stop extracting factors basically depends on when there is only very little ,random” variability left. The nature of this decision is arbitrary; however, various guidelines such as the Kaiser criterion have been developed and are well documented in literature. Factors are ranked in order of merit. The first factor or component has the highest eigenvector sum and represents the most important source of variation in the data. The last factor is the least important process contributing to the variation. Factor loadings (weightings) on the factor loadings tables are interpreted as correlation coefficients between the study variables and the factors [13].

\section{Results and discussion}

Multivariate analysis of facilities management data was subjected through Factor analysis (FA) $[7,9,10]$. The data sets were first summarized (Table 2). From Table 2 it is observed that the coefficients of variation of the variables were the largest for primar input, and primar reverse. The smallest range was for outdoor temperature and temperature hot water Primary. The central heating temperature varies from $24,057{ }^{\circ} \mathrm{C}$ to $57,344{ }^{\circ} \mathrm{C}$ with an average 40,35 . The outdoor temperature varies from $-3,96{ }^{\circ} \mathrm{C}$ to $24,26{ }^{\circ} \mathrm{C}$ with an average $10,21{ }^{\circ} \mathrm{C}$. All the mathematical and statistical computations were made using Statistical Package for Social Sciences version 7. 
Table 2: Descriptive statistics

\begin{tabular}{clllll} 
Variables & Mean & Median & Minimum & Maximum & Std. Dev \\
\hline DS1 & 40,35205 & 38,48741 & 24,05753 & 57,3437 & 10,07078 \\
DS2 & 46,30860 & 46,98534 & 41,80030 & 47,2723 & 1,24094 \\
DS3 & 44,93736 & 45,07842 & 40,73858 & 49,1463 & 2,96086 \\
DS4 & 10,21516 & 10,09491 & $-4,03434$ & 24,2615 & 10,09841 \\
DS5 & 44,29928 & 41,37090 & 26,74429 & 65,8707 & 13,05882 \\
DS6 & 36,49227 & 36,92484 & 20,05276 & 57,2474 & 13,42178 \\
DS7 & 46,70084 & 47,00000 & 44,88642 & 47,2922 & 0,71362 \\
DS8 & 37,47782 & 41,72726 & 5,00000 & 65,8271 & 20,44805 \\
DS9 & 90,31182 & 88,09560 & 73,73784 & 104,4922 & 8,38567 \\
DS10 & 70,79623 & 70,37630 & 60,24239 & 85,9132 & 6,95127 \\
\hline
\end{tabular}

Initial information about the correlation structure of the data set was obtained from the implementation of the selection correlation matrix 10 variables. Correlations fluctuate from 0.15 (for DS2 and DS10) to 0.95 (correlation between the DS6 and DS8), respectively. Correlation coefficients in Table 3 between the evaluated elements larger than 0.5 indicate that there exist high mutual correlation, correlation coefficients less than -0.5 indicate high indirect mutual correlation. The correlation matrix of variables was generated and factors extracted using the varimax rotation. Factor loadings are given in Table 3. To assess the appropriateness of using factor analysis was used KMO test [11]. KMO statistic should take the value 0.73 , suggesting moderate the useful application of factor analysis.

Table 3: Correlation matrix R

\begin{tabular}{lllllllllll} 
& DS1 & DS2 & DS3 & DS4 & DS5 & DS6 & DS7 & DS8 & DS9 & DS10 \\
\hline DS 1 & 1,00 & & & & & & & & & \\
DS 2 & 0,37 & 1,00 & & & & & & & & \\
DS 3 & $-0,57$ & $-0,17$ & 1,00 & & & & & & & \\
DS 4 & $\mathbf{- 0 , 9 2}$ & $-0,46$ & 0,52 & 1,00 & & & & & & \\
DS 5 & $\mathbf{0 , 9 3}$ & 0,43 & $-0,43$ & $\mathbf{- 0 , 9 5}$ & 1,00 & & & & & \\
DS 6 & $\mathbf{0 , 9 4}$ & 0,43 & $-0,52$ & $\mathbf{- 0 , 9 9}$ & $\mathbf{0 , 9 5}$ & 1,00 & & & & \\
DS 7 & $-0,10$ & 0,44 & $-0,14$ & $-0,05$ & 0,05 & 0,02 & 1,00 & & & \\
DS 8 & $\mathbf{0 , 8 4}$ & 0,44 & $-0,44$ & $\mathbf{- 0 , 9 5}$ & $\mathbf{0 , 9 4}$ & $\mathbf{0 , 9 5}$ & 0,13 & 1,00 & & \\
DS 9 & $\mathbf{0 , 9 3}$ & 0,56 & $-0,47$ & $\mathbf{- 0 , 9 3}$ & $\mathbf{0 , 9 3}$ & $\mathbf{0 , 9 2}$ & 0,01 & $\mathbf{0 , 8 5}$ & 1,00 & \\
DS 10 & $-0,46$ & $-0,15$ & 0,48 & 0,49 & $-0,35$ & $-0,50$ & 0,17 & $-0,40$ & $-0,37$ & 1,00 \\
\hline
\end{tabular}

So, factor analysis is appropriate for our data. Next we need to find the eigenvalues of the realized correlation matrix $\mathrm{R}$ to determine the number of factors standing in the background. Eigenvalues are presented in the following table along with the percentage of total variance (Table 4). 
Table 4: Eigenvalues implementation of selective correlation matrix R.

\begin{tabular}{lllll}
\hline Value & Eigenvalue & \% Total variance & $\begin{array}{l}\text { Cumulative } \\
\text { eigen value }\end{array}$ & Cumulative \% \\
\hline $\mathbf{1}$ & 6,417754 & 64,17754 & 6,41775 & 64,1775 \\
$\mathbf{2}$ & 1,412973 & 14,12973 & 7,83073 & 78,3073 \\
$\mathbf{3}$ & 0,937745 & 9,37745 & 8,76847 & 87,6847 \\
$\mathbf{4}$ & 0,609626 & 6,09626 & 9,37810 & 93,7810 \\
$\mathbf{5}$ & 0,399113 & 3,99113 & 9,77721 & 97,7721 \\
$\mathbf{6}$ & 0,129389 & 1,29389 & 9,90660 & 99,0660 \\
$\mathbf{7}$ & 0,040967 & 0,40967 & 9,94757 & 99,4757 \\
$\mathbf{8}$ & 0,038545 & 0,38545 & 9,98611 & 99,8611 \\
$\mathbf{9}$ & 0,010271 & 0,10271 & 9,99638 & 99,9638 \\
$\mathbf{1 0}$ & 0,003615 & 0,03615 & 10,00000 & 100,0000 \\
\hline
\end{tabular}

According to the Kaiser criterion for $\mathrm{R}$ for the number of eigenvalues of the implementation matrix $R$, this is greater than 1 [12]. The Table 4 shows that such eigenvalues there is a three. These three eigenvalues cumulatively explained over $87 \%$ of the total variance, which is also met other criteria. To confirm the appropriate number of factors we use scree plot, which shows the figure.

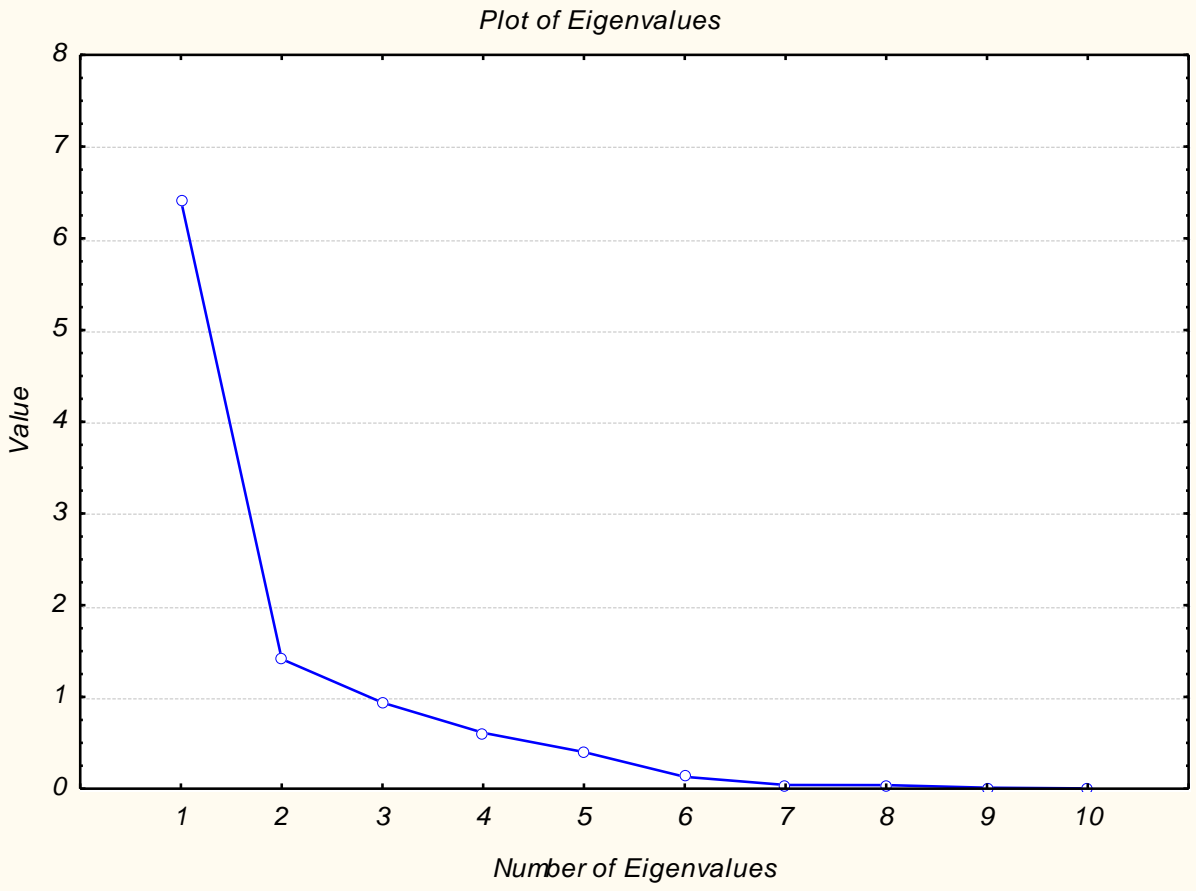

Figure 1: Scree plot

The correlation matrix of variables was generated and factors extracted using the varimax rotation. Factor loadings are given in Table 5. 
Table 5: Factors

\begin{tabular}{cll}
\hline & Factor 1 & Factor 2 \\
\hline DS 1 & 0,960316 & $-0,069500$ \\
DS 2 & 0,449956 & 0,695549 \\
DS 3 & $-0,596074$ & 0,055224 \\
DS 4 & $-0,981805$ & $-0,073390$ \\
DS 5 & 0,950984 & 0,104233 \\
DS 6 & 0,984028 & 0,037719 \\
DS 7 & $-0,013760$ & 0,879350 \\
DS 8 & 0,926548 & 0,148573 \\
DS 9 & 0,941714 & 0,133338 \\
\hline DS 10 & $-0,558136$ & 0,366960 \\
Expl.Var & 6,373618 & 1,457110 \\
Prp. Totl & 0,637362 & 0,145711 \\
\hline
\end{tabular}

The factor analysis generated two significant factors which explained 78,3\% of the variance in data sets. The first factor correlates with DS1, DS5, DS6, DS8, DS9 and indirect with DS4. The second factor correlates with DS7 and weakly correlates with DS2. After rotation the first factor of the total variance in the 10 considered variables is $63.74 \%$. The second factor of the total variance represents $14.57 \%$. The following factors were indicated considering the aspects of the facilities management:

Factor 1 can be interpreted as a high indirect dependence of outdoor temperature with temperature of central heating, Temperature of air conditioning, desired value calculated by the central heating, air condition setpoint and Primar input. High correlation with outdoor temperature means an increase in efficiency of central heating.

Factor 2 can be interpreted as influence of set point DHW.

\section{Conclusion}

The above analysis demonstrates the use of multivariate statistical techniques to study the source/genesis of facilities management parameters in study object. Ten parameters have been monitored on municipality of Košice. Data set was analysed using factor analysis (FA). Quality factor model was assessed by KMO test showed a moderate usefulness (KMO 0,73). Using the method of principal components, we managed to find two standing in the background of the common factors of 10 explanatory variables FA identified two factors responsible for data structure explaining $78,3 \%$ of total variance. Factor 1 characterises the influence of outdoor temperature on temperature of air condition, , desired value calculated by the central heating, air condition setpoint and Primar input. This study shows that factor analysis is a useful method that could assist decision makers in determining the extent of facility management indicators. It could also provide a crude guideline for selecting the priorities of possible preventative measures in the proper of facility management.

\section{References}

[1] Somorová, V. (2007). Facility management - efektívna forma spravovania budov. ASB, 1. 
[2] Vyskočil, V.K. (2006). Podstata řízení podpurnych procesu. Acta Evida, 46, 351-363.

[3] StatSoft Electronic Statistics Textbook. http://www.statsoft.com/textbook/principalcomponents-factor-analysis/.

[4] Documents provided by the municipality of Kosice.

[5] Anazawa, K., Ohmori, H. (2006). The hydrochemistry of surface waters in Andesitic Volcanic area, Norikura volcano, central Japan. Chemosphere, 59, 605-610.

[6] Brown, C.E. (1998). Applied Multivariate Statistics in Geohydrology and Relate Sciences. New York: Springer.

[7] Yidana, S.M.; Duke Ophori, D.; Banoeng-Yakubo, B. (2007) A multivariate statistical analysis of surface water chemistry data NThe Ankobra Basin, Ghana. Journal of Management, 86, 8087.

[8] Sharma, S. (1996). Applied Multivariate Techniques. USA: John Wiley and Sons.

[9] Johnson, R., A.; Wichern, D., W. (1998). Applied multivariate statistical analysis (5th ed.). USA: Prentice Hall.

[10] Millard, S., P.; Neerchal, N., K. (2001). Environmental statistics with S-PLUS. CRC Press, USA.

[11] Eyduran, E., Topal, M. and Sonmez, A.Y. (2010). Use of factor scores in multiple regression analysis for estimation of body weight by several body measurements in brown trouts (Salmo trutta fario). Int. J. Agric. Biol., 12, 611-615.

[12] Suhr, D. (2005). Principal Component Analysis vs. Exploratory Factor Analysis. In SUGI 30 Proceedings, 10-13 April 2005 . Philadelphia, Pennsylvania.

Web: http://www2.sas.com/proceedings/sugi30/203-30.pdf.

[13] Singovszka, E., Balintova, M. (2012). Application Factor Analysis for the Evaluation Surface Water and Sediment Quality. Chemical Engineering Transactions. 26, 183-188. 